\title{
Factors Influencing Malaria Morbidity and Mortality Among Under 15 Years Children in Parts of Ghana: The Role of Guardians' Socio-Demographic Characteristics Demonstrated Through Modelling
}

Kwame Asare ( $\nabla$ kwamsare@hotmail.com )

University of Cape Coast

\section{Research Article}

Keywords: Plasmodium falciparum, Malaria, child health, guardian socio-demographic characteristics, socio-economic model

Posted Date: January 18th, 2021

DOl: https://doi.org/10.21203/rs.3.rs-141821/v1

License: (c) (i) This work is licensed under a Creative Commons Attribution 4.0 International License. Read Full License 


\section{Abstract}

Background To understand the underlying factors that led to failure to achieve the millennium development goal $6 \mathrm{c}$ by Ghana, we modelled guardians' socio-demographic characteristics and the factors that could influence child health to provide directions for improving anti-malaria interventions in Ghana and sub-Sahara Africa.

Methods Clinical data of 274 malaria patients, age up to 15 years, were collected from a cross-sectional study conducted in two districts in the central region of Ghana. Guardians of the children were interviewed to obtain socio-demographic characteristics and factors that could influence child health. The data obtained were analysed using multivariate GLM, type III ANOVA and multilayer perceptron network analysis.

Results Of the 274 children enrolled into the study, $69.34 \%$ were between the age of $0-5$ years. The median parasite density, haemoglobin and platelet were 89,923 $(64,056-149,541)$ parasites/mm3, 8.40 $(4.70-11.60) \mathrm{g} / \mathrm{dL}$ and $126(87-146) \times 10^{\wedge} 9 / \mathrm{L}$ respectively. $12.41 \%$ of the enrolled children had severe clinical conditions. The outcome using multivariate GLM analysis indicate a significant association between the guardians' socio-demographic characteristics and factors that influence child health, $p<0.0001$. CSOC, FPOCCH, DOOSCS, and CS were all influenced by the guardians' occupational status, $p<0.0001$; CSOC and MCID were influenced by the guardians' educational levels, $p<0.0001$ and FPOCCH and MCID were also influenced by guardians age category, $p<0.0001$. The multilayer perceptron network analysis showed that the association between guardians' socio-demographic characteristics and factors that influence child health are affected by several hidden confounding factors.

Conclusion It was demonstrated an association between factors that influence child health care and guardians' socio-demographic characteristics and this is confounded by hidden socio-economic factors and biases through modelling. I, therefore, propose a model called a network of socio-economic progenitors to provide a simple explanation for the underlying factors that influence child health in malaria-endemic areas.

\section{Introduction}

The instigation of multiple malaria interventions to reduce malaria incidence were widely accepted phenomenon to achieve the millennium development goal 6c (MDGs) between 2000 and 2015 [1]. However, Ghana like many sub-Sahara African countries did not make any significant improvement [2, 3]. The implementation of malaria control program has not seen any significant translation to the reduction in malaria prevalence and child mortality, especially in Sub-Saharan Africa $[4,5]$. The World Health Organization (WHO) estimates that $90 \%$ of all global malaria mortality occurs in Africa of which $75 \%$ of the mortality cases are associated with children under five years [6, 7]. Ghana, like most of the subSahara African countries, has a slow reduction in malaria after conscious effects of the implementation 
of malaria interventions [8]. In 2013 alone, Ghana recorded 11.3 million cases with an average of 30,300 malaria cases per day reported in the outpatient departments (OPD) of the health facilities [9].

The empirical variations of healthcare interventions among a set of the population have given rise to many health-associated behavioural studies across the world [10]. These studies are conducted to explicitly identify factors associated with health and health-seeking behaviours in a given community to provide patterns for the variations in healthcare interventions $[10,11]$. The results of such studies provide the baseline data for evaluation of interventions such as the use of insecticide-treated bed nets, and indoor residual spraying programs $[12,13]$. However, no comprehensive direction to consolidate the running intervention programs are suggested by these studies to mitigate the health risks within a given community. Although there are interesting associations between social, cultural, and economic factors as well as disease patterns and issues related to health services and community health, yet these results have not shown to have increased the efficiency of integrated malaria control programs in reducing malaria morbidity and mortality especially among children in Ghana $[14,15]$.

Malaria is a treatable disease with highly efficacious artemisinin-based combination therapies (ACTs) which has an absolute cure rate [16]. Therefore, malaria infection is not expected to cause a death toll on children especially among those under five years. Delayed diagnosis and treatment have negative impacts on malaria morbidity and mortality [17]. The desire to halt and reverse malaria prevalence has fallen short due to the unrealized complexity associated with malaria morbidity and mortality. The ability of individuals to identify the classical symptoms of malaria is an important stimulus for voluntary and conscious effort for selecting and pursuing a prompt treatment of malaria. Unambiguously, malaria mortality is associated with a problem for recognising the symptoms and making a prompt decision to select the appropriate treatment for it [18]. The decision to seek treatment for a sick child as shown in literature is influenced by socio-demographic characteristics, socio-cultural and economic factors [19,20]. To understand these inherent factors that influence guardians' health-seeking behaviours that impact on the child health, we modelled the guardians' socio-demographic characteristics and the factors that influence child health to provide direction for improvement of malaria interventions and to reduce malaria child mortality in Ghana.

\section{Methods}

\section{Study sites}

A cross-sectional study was conducted in two districts in the Central region of Ghana. The Central region occupies an area of 9826 square kilometres with an estimated population of $2,107,209$. The region which is bordered by Ashanti, Eastern, Greater Accra and the Atlantic Ocean is the second-most densely populated after Greater Accra region in Ghana. Samples were collected from two municipal and two district hospitals in the Region: Assin North and Twifo Hemang Lower Denkyira districts (figure 1). Both districts lie at semi-equatorial climate zone with annual rainfall ranging between 1750 and $2000 \mathrm{~mm}$ 
which peaks in June and October. These coincide with the highest malaria prevalence in the year, although the districts are holoendemic.

\section{The rationale of the study}

The purpose of the study was to use real-time field data to model guardians' socio-demographic characteristics and the factors that influence child's clinical condition (child health) in malaria-endemic communities that have adopted all the national malaria interventions yet without significant improvement in malaria incidence especially among children under-five years.

\section{Sampling and data collection}

Children between the age 0-15 years who visited the Twifo Praso and St. Francis Xavier health facilities at Twifo Hemang Lower Denkyira and Assin North districts respectively, who were diagnosed with malaria were enrolled into the study. Clinical data of the children were extracted from the hospital records. The guardians were interviewed using a standardised questionnaire to obtain guardians' socio-demographic characteristics which include Occupational status of Guardian (OCSG), Educational level of Guardian (EDULG), Sex of Guardian (SOG) and Age category of Guardian (AGECOG). other factors which could have influenced the clinical condition of the children such as Clinical severity of the child (CSOC), Days of on-set of symptoms before hospital visit (DOOSCS), the first point of call for child health (FPOCCH), Clinical symptoms (CS) and Malaria control intervention adopted by Guardian (MCID) were obtained.

A total of 274 children who were enrolled in the study and their blood samples taken. Haemoglobin concentration (HB), Mean Cell Haemoglobin ( $\mathrm{MCH}$ ), and platelet count were obtained using Sysmex KX21 haematology analyser. The mean values of the results were determined for each participant.

Thick blood films were also prepared, stained with Giemsa and parasitaemia estimated for each sample under a light microscope. The parasitaemia levels, haemoglobin levels and general classification of the child condition by the clinicians were used to determine clinical severity.

\section{Data analysis}

The data collected were entered using Microsoft access (MS access) 2010 and imported to SPSS statistical software version 16 (SPSS Inc.) for analysis. All data were categorised, analysed descriptively and presented as proportions. The clinical characteristics data was measured for its central tendencies and presented as medians and ranges. The effects of the guardians' socio-demographic characteristics on the factors that influence child health were analysed using Multivariate Generalized module test (Multivariate GLM test) and Type III ANOVA statistics. The statistic significant was assumed at $p<0.05$. The patterns of association between guardians' socio-demographic characteristics and the factors that influence child health were analysed using multilayer perceptron network analysis.

\section{Results}




\section{Socio-demographic data of guardians}

A total of 274 subjects were interviewed to identify factors that influence child health in malaria-endemic districts in the Central region of Ghana. Majority of the guardians (73.4\%) were above 25 years of age with $216(78.8 \%)$ and $58(21.2 \%)$ representing Females and males respectively. The educational level of the participants ranges from informal education to tertiary education. Participants with informal education were 52 (19.0\%), middle school/JSS 106 (38.7\%), secondary school/vocational education 97 (35.4\%), and tertiary education $12(4.4 \%)$. The main occupations of the study participants were trading/business 92 (33.6\%), pension 9 (3.3\%), farming 55 (20.1\%), hairdressing/seamstress 42 (15.3\%) whilst the remaining 20 (7.3\%) were unemployed (Table 1).

\section{Clinical data of children}

274 children whose Guardians were enrolled in the study were diagnosed with malaria and presented in mild to severe clinical conditions. About $190(69.34 \%)$ of the children were within the age category $0-5$ years whilst $84(30.66 \%)$ were within 6-15 years. The median clinical presentations were; parasite density 89923 (64056-149541) parasites/mm3, haemoglobin concentration 8.40 (4.70-11.60) g/dl, and platelet count $126(87-146) \times 10^{\wedge} 9 / \mathrm{L}$ of blood (Table 2$)$.

\section{Factors influencing child health}

The factors that influence child health were identified using both clinical data and interviews. The clinical condition of the children whose guardians were enrolled in the study ranges from mild clinical condition $154(56.20 \%)$ to severe clinical condition $34(12.41 \%)$. The main clinical symptoms of the children that were identified by the guardians included high body temperature 233 (85.04\%), less activeness 153 (55.84\%), loss of appetite 189 (68.98\%), and excessive crying 154 (56.20\%). Most of the guardians sought treatment for their children at the hospital 89 (32.5\%) whilst the rest resorted to drug/chemical shops 60 (21.9\%), clinic/health centres $58(21.2 \%)$ and pharmacy shops 51 (18.6\%). Majority of the guardians waited 2-3 days after clinical symptoms of their wards before seeking medical treatment 181 (66.1\%). Guardians also adopted some form of malaria prevention intervention such as the usage of mosquito net, mosquito spraying, and mosquito coils (Table 3 ).

\section{Effect of guardians' socio-demographic characteristics on factors of child health}

Guardians' socio-demographic characteristics were modelled to test for its canonic effects on the factors that influence child health using multivariate GLM statistics. The multivariate GLM test showed significant association between guardians' socio-demographic characteristics and the factors that influence child health [CSOC $F(6,516)=41.059 a$, Wilks' $L=0.45, p<0.0001$; FPOCCH F $(12,682.895)$ $=12.541$, Wilks' $L=0.59, p<0.0001 ;$ DOOSCS F $(6,516)=2.506 \mathrm{~b}$, Wilks' $L=0.944, p=0.021 ; \operatorname{CS} F(3,258)$ $=36.523$, Wilks' L=0.702, $p<0.0001$; and MCID F $(9,628.055)=57.908$, Wilks' L=0.23, $p<0.0001]$ (Table 4). To identify the specific guardians' socio-demographic characteristics that have an overall effect on the factors that influence child health, the associations were further tested using type-III ANOVA statistics. 
The analysis indicated that CSOC $(F=98.997, S S=33.224, d f=2), F P O C C H ~(F=29.838, S S=20.028, d f=4)$, $\operatorname{DooSCS}(F=7.655, S S=2.569, \mathrm{df}=2), \mathrm{CS}(\mathrm{F}=109.977, \mathrm{SS}=18.455, \mathrm{df}=1)$ and $\mathrm{MCID}(\mathrm{F}=11.827, \mathrm{SS}=5.954$, $d f=3$ ) were all influenced by the occupational status of the guardian, $p<0.0001$. On the other hand, CSOC, FPOCCH, and MCID were also influenced by educational level of guardians with $p$ values of $<0.0001$, 0.076 , and $<0.0001$ respectively. It was also revealed that $\mathrm{FPOCCH}$ and $\mathrm{MCID}$ were the only factors that were influenced by the guardian age category, $p<0.0001$. However, the gender of the guardians did not show any statistical significance with the factors influencing child health (Table 5).

\section{Patterns between guardians' socio-demographic characteristics and factors influencing child health}

The Wilk's Lambda statistics showed that there is some significant proportion of variance in the factors that influence child health which could not be explained by the guardians' socio-demographic characteristics (Table 4). To further model the association to have some insight into the underlying patterns within the data, we employed multilayer perceptron network analysis. The model predicted strong confidence indicating a suitable pattern between guardians' socio-demographic characteristics and the factors influencing child health (SSE=13.899, 186 (67.9\%) in training, and 88 (32.1\%) in testing from the total sample of 274). The relative error for scale dependents in training sets were $0 \mathrm{CSG}=0.043$, $E D U L G=0.058, S O G=0.0$, and $A G E C O G=0.050$ with only $3.8 \%(S S E=13.899$, error $=0.038)$. The overall misclassification of training sets was $4.3 \%$ (SSE $=9.193$, error $=0.043$ ) compared to testing sets with scale dependents determined $\mathrm{OCSG}=0.053, \mathrm{EDULG}=0.047$, $\mathrm{SOG}=0.0$, and $\mathrm{AGECOG}=0.08$. This predicts $96.2 \%$ and $95.7 \%$ accuracy for the association between guardians' socio-demographic characteristics and factors that influencing child health respectively (Table 6). The graphical presentation of the association between guardians' socio-demographic characteristics and the factors influencing child health is shown in figure 2. The figure 2 gives a complete insight into the underlying patterns such as biases and hidden factors ( $H$ [1:1-9]). The nature of the underlying factors on the associations either reduces the effects of the hidden factors (as shown by blue lines; synaptic weight $<0$ ) or increases the effects of the hidden factors (as shown by grey lines; synaptic weight $>0$ ). This analysis provides a potential tool for data mining or knowledge discoveries that can impact interventions aimed at improving child health in malaria-endemic areas.

\section{Impact of Socio-economic progenitors on child health}

The multilayer perceptron analysis showed that the effects of guardians' socio-demographic characteristics on child health are influenced by some hidden factors (Figure 2). For further elucidation of the interactions, we propose a network of socio-economic progenitors that impact on child health. Understanding the elements that affect child health can serve as the foundation for the promotion of health interventions. Therefore, the awareness of socio-economic factors has become an indispensable tool to model effective interventional measures. To significantly reduced malaria prevalence among children in the malaria-endemic areas, our ability to predict and evaluate accurately the determinants that can either affect the introduction of health-related interventions negatively or positively is required. Our socio-economic progenitor network provides easy visualisation, identification, prediction and evaluation 
of factors that affect health-related interventions. The model predicts health-seeking behaviours, issues related to health services, social, cultural, and economic factors as the major hidden factors that affect the association between guardians' socio-demographic characteristics and the factors influencing child health in malaria-endemic communities (figure 3).

\section{Discussion}

Identification of specific guardian's socio-demographic characteristics that impact malaria morbidity and mortality among children is essential for the formulation, prioritization and implementation of malaria interventions in disease-endemic regions [21, 22]. The current anti-malarial interventions have the potential to eliminate malaria, however, Ghana like many other sub-Sahara African countries could not achieve a significant reduction in malaria incidence especially among children after adaptation and implementation of malaria interventions [23-26]. A syndicate of social, cultural, behavioural, religious and economic factors have been implicated to influence malaria morbidity and mortality within malariaendemic communities [27-29]. Although these factors are well studied, the findings are yet to be translated into effective antimalarial interventions. This requires a conscientious understanding of the shrouded dynamism of malaria morbidity and mortality, especially among children. In this study, we have modelled guardian's socio-demographic factors and factors influencing child health in malaria-endemic regions in real-time to provide a roadmap for the design of effective antimalarial interventions in Ghana.

This study showed that a sizable number of the enrolled children had poor prognosis which could have been prevented with early detection and selection of appropriate treatment regimen. Delay in pre-hospital consultation for malaria treatment in malaria-endemic countries could account for the severity of the observed morbidity and mortality [30-32]. Anti-malaria controls require early diagnosis, absolute treatment and the use of appropriate interventions. Nearly half of the participating guardian's practised self-medication (by purchasing drugs from pharmacy and drug stores or used traditional medicines) without any diagnosis. These behavioural practices by guardians have negative implications on malaria control strategies resulting in the induction of drug resistance, delay in malaria diagnosis and treatment culminating in complicated malaria conditions among the children.

Awareness of the symptoms of a disease is an indispensable tool or knowledge for seeking appropriate treatment for a sick child. Such an action has a direct impact on the clinical presentation and the overall prognosis of a given disease. The clinical symptoms that stimulated the eagerness of the guardians to seek treatment for their children were very diverse. Interestingly, even after the detection of the disease symptoms, it took two to three days for most guardians to seek treatment for their children at different preferential sources. Although the outcome of a child's health depends on these factors, guardians overlook the importance of these factors. However, the underlying factors which promote such behaviour and practices by guardians are very difficult to intuit. For instance, the reasons for waiting two to three days before seeking treatment for a sick child and what influences their choice of place for treatment are all unknown. Clinical data indicated that the participating children had severe to moderate malaria infections with high parasite densities, anaemia and mild thrombocytopenic conditions. Severe anaemia 
has been well characterised as an important cause of malaria mortality mostly among children [33, 34]. Although thrombocytopenia had not been associated with malaria mortality, a recent study has shown that severe thrombocytopenia has a 2.4 -fold risk of severe morbidity leading to hospital admission and 4.7-fold mortality among falciparum malaria infection [35]. The concurrent thrombocytopenia and anaemia with high parasite densities are a risk for severe morbidity and mortality as well as later disabilities due to malaria. Malaria morbidity and mortality among children have been attributed to insufficient protective immunity to protect them from the severe forms of the disease [36]. Malaria prevention, prompt disease detection and appropriate treatment which are important to resolve and restore child health depend on guardians' socio-demographic factors [37, 38].

Several studies have highlighted the importance of social and behavioural effects on the design and implementation of effective antimalarial interventions in malaria-endemic areas [28, 39]. However, how directly these factors impact on the interventions are still not understood. Maternal age, education and socioeconomics have been demonstrated to have a significant association with malaria [40,41].

Education has an impact on health-seeking behaviours whilst increasing socioeconomic status has an association with the prevention of severe clinical conditions among children and effective implementation of health care interventions [42]. This study has shown that the guardians' educational level significantly influences CSOC, FPOCCH and MCID. It has been shown that children whose mothers have less than primary school education have a higher odd of developing cerebral malaria [43]. Furthermore, mothers' education has shown to be a predictive factor for adopting disease prevention strategies and treatment-seeking behaviour [44].

The study also revealed that the occupation of Guardians significantly affects the health of the child. Mothers' occupation and location have been linked respectively with high malaria parasitaemia and clinical severity among children $[45,46]$. Several other studies have also shown an association between income and child health, suggesting that low-income families are less likely to seek prompt treatment for their sick children [47]. Although the study did not directly measure the income of the participants most of them were traders, farmers and seamstresses who delay in seeking treatment for their ill children. This suggests that many of the participants work more hours to keep up with living expenses and to reduce their poor living conditions leading to the neglect of taking a keen interest in the health of their children. Hence many changes, clinical signs and symptoms of their children are sometimes unnoticed in time. For instance, many of the guardians wake up very early in the morning to undertake their ventures with little or no attention to the health of their children. Unfortunately, many of the children especially those underfive years become exposed to several health risks because they are carried along by their guardians especially mothers as they embark on their chosen occupations.

In agreement with Siri, there are suspicions of inherent biases in socioeconomic factors and malaria infection [48]. Our multivariate analysis showed that socio-demographic characteristics of guardians alone could not explain the significant variance in the factors that influence child health in malariaendemic areas. To have insight into the underlying variance and provide an explanation for the association between socio-demographic characteristics and the factors that influence child health, we 
further analysed the association using multilayer perceptron network analysis. The results predicted that each socio-demographic characteristic measured in this study was influenced by several hidden factors which intend to affect the factors that influence child health in malaria-endemic areas. We, therefore, propose a network of socio-economic progenitors to explain the underlying variances by factoring into the model social, cultural, economic factors as well as issues related to health services and healthseeking behaviour by guardians for children under 15 years in malaria-endemic areas. Each of the progenitors used in this model is a determinant of child health $[29,40]$. However, the interaction between the projectors that affect the overall health of a child is yet to be accessed. For instance, health-seeking behaviour by guardians for their children is affected by multiple of factors such as socio-demographic characteristics, issues related to health services, social, cultural and economic factors as confounding factors that influence the outcome of the health of the child $[40,49]$. Similarly, guardians' sociodemographic characteristics are also influenced by social, cultural and economic factors. These explain the hidden confounding factors that affect the health of children in malaria-endemic areas. That is why using a single progenitor to measure the outcome of children health often results in inconsistencies in the results $[40,42,50]$. Health seeking behaviours varies from person to person which could be attributed to factors such as a person's perception of sickness, belief in the efficacy of a drug or herbal medicine, poverty, cultural or social believes and access to health services [51-53]. We propose a simple unambiguous model that explains the underlying inherent problems associated with socioeconomic factors as determinants of child health in malaria-endemic areas. This model provides a clear direction that can be used to design effective anti-malaria interventions to reduce malaria morbidity and mortality in children especially in sub-Sahara Africa where malaria interventions have failed to yield expected results.

\section{Conclusion}

This study has revealed the association between guardians' socio-demographic factors and the factors that influence child health. However, these associations are influenced by a network of socio-economic progenitors with hidden factors and biases. These hidden factors and biases explain why previously observed associations have not to help to improve anti-malaria interventions, especially in sub-Sahara Africa. The proposed network of socio-economic progenitors provides a simple explanation and the pattern of confounding factors that influence the outcome of child health in malaria-endemic areas. This model provides roadmaps for validation, verification and provides a potential tool for designing effective anti-malaria interventions to reduced malaria mortality among children in Ghana and other sub-Sahara African countries.

\section{Definition Of Terms}

CSOC [Clinical severity of the child]

FPOCCH [First point of call for child health] 
DOOSCS [Days of on-set of child symptoms before the hospital visit]

CS [Clinical symptoms]

MCID [Malaria control intervention adopted by Guardian]

OCSG [Occupational status of Guardian]

EDULG [Educational level of Guardian]

SOG [Sex of Guardian]

AGECOG [Age category of Guardian]

\section{Declarations}

\section{Ethical clearance and consent to participate}

The study protocol was reviewed and approved by the Ghana Health Service Ethics Committee (GHS-ERC17/01/12) and the University of Cape Coast Institutional Review Board (UCCIRB/28/09/3.1.1). The purpose of the study was explained to the guardian and written informed consent were obtained before interviewed. The study posed no risk to the subjects.

\section{Consent for publication}

Not applicable

\section{Availability of data and materials}

Not applicable

\section{Funding}

No funding agent

\section{Competing interests}

None declared

\section{Human and Animal Rights}

Human participants, human material and human data were collected, used or performed in accordance with the 2008 Declaration of Helsinki.

\section{Author contributions statement}

A.K.K designed the study, collected the samples, performed the statistical analysis and wrote the paper. 


\section{Acknowledgements}

I am grateful to the Department of Biomedical Sciences, University of Cape Coast laboratory and the medical staffs of St. Francis Xavier hospital, and Twifo Praso district hospital for their technical support.

\section{References}

1. Shrivastava SR, Shrivastava PS, Ramasamy J. Millennium development goal target to reverse the global malaria incidence accomplished: The ground reality and what next?. Annals of Tropical Medicine and Public Health. 2016 May 1;9(3):141.

2. Nnamuchi O. Millennium Developmental Goal 6 and the Trifecta of HIV/AIDS, Malaria, and Tuberculosis in Africa: A Human Rights Analysis. Denv. J. Int'I L. \& Pol'y. 2013;42:247.

3. Nnamuchi O. Health and millennium development goals in Africa: deconstructing the thorny path to success. InThe Right to Health 2014 (pp. 3-41). TMC Asser Press, The Hague.

4. Jakubowski A, Stearns SC, Kruk ME, Angeles G, Thirumurthy H. The US President's Malaria Initiative and under-5 child mortality in sub-Saharan Africa: A difference-in-differences analysis. PLoS medicine. 2017 Jun 13;14(6):e1002319.

5. Bhatt S, Weiss DJ, Cameron E, Bisanzio D, Mappin B, Dalrymple U, Battle KE, Moyes CL, Henry A, Eckhoff PA, Wenger EA. The effect of malaria control on Plasmodium falciparum in Africa between 2000 and 2015. Nature. 2015 Oct;526(7572):207-11.

6. Pizzitutti F, Pan W, Feingold B, Zaitchik B, Álvarez CA, Mena CF. Out of the net: An agent-based model to study human movements influence on local-scale malaria transmission. PloS one. $2018 \mathrm{Mar}$ 6;13(3):e0193493.

7. Castro MC. Malaria transmission and prospects for malaria eradication: the role of the environment. Cold Spring Harbor Perspectives in Medicine. 2017 Oct 1;7(10):a025601.

8. Omona J. Social marketing and the fight against malaria in Africa: population services international (PSI) and insecticide treated nets (ITNS). East African journal of public health. 2009 Dec 1;6(3).

9. Yao KM, Obeng F, Ntajal J, Tounou AK, Kone B. Vulnerability of farming communities to malaria in the Bole district, Ghana. Parasite epidemiology and control. 2018 Nov 1;3(4):e00073.

10. Michie S, West R, Sheals K, Godinho CA. Evaluating the effectiveness of behavior change techniques in health-related behavior: a scoping review of methods used. Translational behavioral medicine. 2018 Apr;8(2):212-24.

11. Michie S, Yardley L, West R, Patrick K, Greaves F. Developing and evaluating digital interventions to promote behavior change in health and health care: recommendations resulting from an international workshop. Journal of medical Internet research. 2017;19(6):e232.

12. Protopopoff N, Mosha JF, Lukole E, Charlwood JD, Wright A, Mwalimu CD, Manjurano A, Mosha FW, Kisinza W, Kleinschmidt I, Rowland M. Effectiveness of a long-lasting piperonyl butoxide-treated insecticidal net and indoor residual spray interventions, separately and together, against malaria 
transmitted by pyrethroid-resistant mosquitoes: a cluster, randomised controlled, two-by-two factorial design trial. The Lancet. 2018 Apr 21;391(10130):1577-88.

13. Dengela D, Seyoum A, Lucas B, Johns B, George K, Belemvire A, Caranci A, Norris LC, Fornadel CM. Multi-country assessment of residual bio-efficacy of insecticides used for indoor residual spraying in malaria control on different surface types: results from program monitoring in $17 \mathrm{PMI} /$ USAIDsupported IRS countries. Parasites \& vectors. 2018 Dec;11(1):1-4.

14. Afoakwah $C$, Deng $X$, Onur I. Malaria infection among children under-five: the use of large-scale interventions in Ghana. BMC public health. 2018 Dec 1;18(1):536.

15. Oo WH, Gold L, Moore K, Agius PA, Fowkes FJ. The impact of community-delivered models of malaria control and elimination: A systematic review. Malaria journal. 2019 Dec 1;18(1):269.

16. Makhoba XH, Viegas Jr C, Mosa RA, Viegas FP, Pooe OJ. Potential impact of the multi-target drug approach in the treatment of some complex diseases. Drug Design, Development and Therapy. 2020;14:3235.

17. Rogerson SJ, Beeson JG, Laman M, Poespoprodjo JR, William T, Simpson JA, Price RN. Identifying and combating the impacts of COVID-19 on malaria. BMC medicine. 2020 Dec;18(1):1-7.

18. Landier J, Parker DM, Thu AM, Carrara VI, Lwin KM, Bonnington CA, Pukrittayakamee S, Delmas G, Nosten FH. The role of early detection and treatment in malaria elimination. Malaria Journal. 2016 Dec 1;15(1):363.

19. Jalu MT, Ahmed A, Hashi A, Tekilu A. Exploring barriers to reproductive, maternal, child and neonatal (RMNCH) health-seeking behaviors in Somali region, Ethiopia. PLoS one. 2019 Mar 15;14(3):e0212227.

20. Das M, Angeli F, Krumeich AJ, van Schayck OC. The gendered experience with respect to healthseeking behaviour in an urban slum of Kolkata, India. International journal for equity in health. 2018 Dec;17(1):1-4.

21. Makaula P, Funsanani M, Mamba KC, Musaya J, Bloch P. Strengthening primary health care at district-level in Malawi-determining the coverage, costs and benefits of community-directed interventions. BMC health services research. 2019 Dec;19(1):509.

22. Nambuusi BB, Ssempiira J, Makumbi FE, Kasasa S, Vounatsou P. Associations and contribution of childhood diseases to fever risk among children less than five years in Uganda. Journal of Global Health Reports. 2020 Jun 16;4:e2020052.

23. Kitojo C, Chacky F, Kigadye ES, Mugasa JP, Lusasi A, Mohamed A, Walker P, Reaves EJ, Gutman JR, Ishengoma DS. Evaluation of a single screen and treat strategy to detect asymptomatic malaria among pregnant women from selected health facilities in Lindi region, Tanzania. Malaria Journal. 2020 Dec;19(1):1-8.

24. Pacifici GM. Clinical Pharmacology of the Antimalarial Artemisinin-Based Combination and other Artemisinins in Children. International Journal of Pediatrics. 2018 Jul 1;6(7):7901-28.

25. Wiafe-Amoako F. Africa 2019-2020. Rowman \& Littlefield; 2019 Sep 25. 
26. Pilkington G, Panday S, Khatib MN, Kotas E, Simkhada P, Hill RA, Jones L. The effectiveness of community engagement and participation approaches in low and middle income countries: a review of systematic reviews with particular reference to the countries of South Asia.

27. Lyttleton C. Deviance and resistance: Malaria elimination in the greater Mekong subregion. Social Science \& Medicine. 2016 Feb 1;150:144-52.

28. Dhiman S. Are malaria elimination efforts on right track? An analysis of gains achieved and challenges ahead. Infectious diseases of poverty. 2019 Dec;8(1):1-9.

29. Anyanwu PE, Fulton J, Evans E, Paget T. Exploring the role of socioeconomic factors in the development and spread of anti-malarial drug resistance: a qualitative study. Malaria journal. 2017 Dec;16(1):1-5.

30. Orimadegun AE, llesanmi KS. Mothers' understanding of childhood malaria and practices in rural communities of Ise-Orun, Nigeria: implications for malaria control. Journal of Family Medicine and Primary Care. 2015 Apr;4(2):226.

31. Herdman MT, Maude RJ, Chowdhury MS, Kingston HW, Jeeyapant A, Samad R, Karim R, Dondorp AM, Hossain MA. The relationship between poverty and healthcare seeking among patients hospitalized with acute febrile illnesses in Chittagong, Bangladesh. PLoS One. 2016 Apr 7;11(4):e0152965.

32. Ilunga-llunga F, Levêque A, Ngongo LO, Laokri S, Dramaix M. Treatment-seeking paths in the management of severe malaria in children under 15 years of age attended in reference hospitals of Kinshasa, Democratic Republic of Congo. Tropical Medicine and Health. 2014.

33. Patriani D, Arguni E, Kenangalem E, Dini S, Sugiarto P, Hasanuddin A, Lampah DA, Douglas NM, Anstey NM, Simpson JA, Price RN. Early and late mortality after malaria in young children in Papua, Indonesia. BMC infectious diseases. 2019 Dec 1;19(1):922.

34. Chaparro CM, Suchdev PS. Anemia epidemiology, pathophysiology, and etiology in low-and middleincome countries. Annals of the New York Academy of Sciences. 2019 Aug;1450(1):15.

35. Lampah DA, Yeo TW, Malloy M, Kenangalem E, Douglas NM, Ronaldo D, Sugiarto P, Simpson JA, Poespoprodjo JR, Anstey NM, Price RN. Severe malarial thrombocytopenia: a risk factor for mortality in Papua, Indonesia. The Journal of infectious diseases. 2015 Feb 15;211(4):623-34.

36. Kamau A, Mtanje G, Mataza C, Mwambingu G, Mturi N, Mohammed S, Ong'ayo G, Nyutu G, Nyaguara A, Bejon P, Snow RW. Malaria infection, disease and mortality among children and adults on the coast of Kenya. Malaria journal. 2020 Dec;19(1):1-2.

37. Abbey M, Chinbuah MA, Gyapong M, Bartholomew LK, van den Borne B. Community perceptions and practices of treatment seeking for childhood pneumonia: a mixed methods study in a rural district, Ghana. BMC Public Health. 2016 Dec 1;16(1):848.

38. Makenga G, Baraka V, Francis F, Nakato S, Gesase S, Mtove G, Madebe R, Kyaruzi E, Minja DT, Lusingu JP. Effectiveness and safety of intermittent preventive treatment for malaria using either dihydroartemisinin-piperaquine or artesunate-amodiaquine in reducing malaria related morbidities 
and improving cognitive ability in school-aged children in Tanzania: A study protocol for a controlled randomised trial. Contemporary Clinical Trials Communications. 2020 Feb 20:100546.

39. Nofal SD, Peto TJ, Adhikari B, Tripura R, Callery J, Bui TM, von Seidlein L, Pell C. How can interventions that target forest-goers be tailored to accelerate malaria elimination in the Greater Mekong Subregion? A systematic review of the qualitative literature. Malaria journal. 2019 Dec 1;18(1):32.

40. Balogun SA, Yusuff HA, Yusuf KQ, Al-Shenqiti AM, Balogun MT, Tettey P. Maternal education and child immunization: the mediating roles of maternal literacy and socioeconomic status. The Pan African Medical Journal. 2017;26.

41. Mpimbaza A, Ndeezi G, Katahoire A, Rosenthal PJ, Karamagi C. Demographic, socioeconomic, and geographic factors leading to severe malaria and delayed care seeking in Ugandan children: a casecontrol study. The American journal of tropical medicine and hygiene. 2017 Nov 8;97(5):1513-23.

42. Sultana M, Sarker AR, Sheikh N, Akram R, Ali N, Mahumud RA, Alam NH. Prevalence, determinants and health care-seeking behavior of childhood acute respiratory tract infections in Bangladesh. PloS one. 2019 Jan 10;14(1):e0210433.

43. Oyedeji OA, Oluwayemi IO, Afolabi AA, Bolaji O, Fadew FF. Severe malaria at a tetiary paediatric emergency unit in South West Nigeria. International Journal of Medical Sciences. 2010;4(6):352-6.

44. Adhikari B, Phommasone K, Pongvongsa T, Koummarasy P, Soundala X, Henriques G, Sirithiranont P, Parker DM, von Seidlein L, White NJ, Day NP. Treatment-seeking behaviour for febrile illnesses and its implications for malaria control and elimination in Savannakhet Province, Lao PDR (Laos): a mixed method study. BMC health services research. 2019 Dec 1;19(1):252.

45. Papaioannou I, Utzinger J, Vounatsou P. Malaria-anemia comorbidity prevalence as a measure of malaria-related deaths in sub-Saharan Africa. Scientific reports. 2019 Aug 5;9(1):1-9.

46. Wegmüller R, Bentil H, Wirth JP, Petry N, Tanumihardjo SA, Allen L, Williams TN, Selenje L, Mahama A, Amoaful E, Steiner-Asiedu M. Anemia, micronutrient deficiencies, malaria, hemoglobinopathies and malnutrition in young children and non-pregnant women in Ghana: Findings from a national survey. PloS one. 2020 Jan 30;15(1):e0228258.

47. Anaba U, Hutchinson PL, Abegunde D, White Johansson E. Pneumonia-related ideations, careseeking, and treatment behaviors among children under 2 years with pneumonia symptoms in northwestern Nigeria. Pediatric Pulmonology. 2020 Jun;55:S91-103.

48. Siri JG. Independent associations of maternal education and household wealth with malaria risk in children. Ecology and Society. 2014 Mar 1;19(1).s

49. Bywaters P, Scourfield J, Webb C, Morris K, Featherstone B, Brady G, Jones C, Sparks T. Paradoxical evidence on ethnic inequities in child welfare: Towards a research agenda. Children and Youth Services Review. 2019 Jan 1;96:145-54.

50. Quiroz Barrios DC. To the search of the cultural print left by malaria: evidence from the Sub-Saharan Africa. 
51. Hjelm K, Atwine F. Health-care seeking behaviour among persons with diabetes in Uganda: an interview study. BMC International Health and Human Rights. 2011 Dec;11(1):1-8.

52. Rogers AT. Exploring health beliefs and care-seeking behaviors of older USA-dwelling Mexicans and Mexican-Americans. Ethnicity \& health. 2010 Dec 1;15(6):581-99.

53. Mbonye AK, Neema S, Magnussen P. Preventing malaria in pregnancy: a study of perceptions and policy implications in Mukono district, Uganda. Health policy and planning. 2006 Jan 1;21(1):17-26.

\section{Tables}

Table 1: Guardians' socio-demographic data 


\begin{tabular}{|ll|}
\hline Variables & $\mathrm{N}(\%)$ \\
\hline Sex of Guardian & $58(21.2 \%)$ \\
\hline Male & $216(78.8 \%)$ \\
\hline Female & \\
\hline Age category of Guardian & $73(26.6 \%)$ \\
\hline$<25$ years & $201(73.4 \%)$ \\
\hline$>25$ years & \\
\hline Educational level of Guardian & $7(2.6 \%)$ \\
\hline Primary school & $106(38.7 \%)$ \\
\hline Middle school/ JSS & $97(35.4 \%)$ \\
\hline Secondary school/ Voc-tech. & $12(4.4 \%)$ \\
\hline College/ tertiary education & $52(19.0 \%)$ \\
\hline informal education & \\
\hline Occupational status of Guardian & \\
\hline Farming & $55(20.1 \%)$ \\
\hline Hair dresser/ Seamstress & $42(15.3 \%)$ \\
\hline Driver & $25(9.1 \%)$ \\
\hline Teacher/ government worker & $16(5.8 \%)$ \\
\hline Trading/ business & $92(33.6 \%)$ \\
\hline Artisan/ Mason & $20(7.3 \%)$ \\
\hline Galamsey/ mines worker & $9(3.3 \%)$ \\
\hline Unemployed & \\
\hline Pension & \\
\hline
\end{tabular}

Table 2: Clinical characteristics of children whose Guardians were enrolled into the study 


\begin{tabular}{|ll|}
\hline Characteristics & Median (Range) \\
\hline Malaria parasites density $(\mathrm{N} / \mathrm{mm} 3)$ & $89928(64,056-149,541)$ \\
\hline Haemoglobin $(\mathrm{g} / \mathrm{dl})$ & $8.4(4.70-11.60)$ \\
\hline Mean Cell Haemoglobin $(\mathrm{pg})$ & $24.8(22.45-27.20)$ \\
\hline Platelet count $\left(10^{\wedge} 9 / \mathrm{L}\right)$ & $126(87.00-146.00)$ \\
\hline
\end{tabular}

Table 3: Factors that influence child health 


\begin{tabular}{|ll|}
\hline Variables & $\mathrm{N}(\%)$ \\
\hline Age category & \\
\hline $0-5$ years N (\%) & $190(69.34 \%)$ \\
\hline $6-15$ years N (\%) & $84(30.66 \%)$ \\
\hline Clinical severity* & \\
\hline Severe & $34(12.41 \%)$ \\
\hline Moderate & $86(31.39 \%)$ \\
\hline Mild & $154(56.20 \%)$ \\
\hline Clinical symptoms & \\
\hline High body temperature & $233(85.04 \%)$ \\
\hline Less active & $153(55.84 \%)$ \\
\hline Vomiting & $45(16.42 \%)$ \\
\hline Headache & $65(23.72 \%)$ \\
\hline Loss of appetite & $189(68.98 \%)$ \\
\hline Stomach ache & $54(19.71 \%)$ \\
\hline Diarrhea & $32(11.68 \%)$ \\
\hline Convulsion & $19(6.93 \%)$ \\
\hline Cough & $23(8.39 \%)$ \\
\hline Excessive crying & $154(56.20 \%)$ \\
\hline First point of call for child health & \\
\hline Hospital & $60(21.9 \%)$ \\
\hline Clinic /health centre & $58(21.2 \%)$ \\
\hline Pharmacy shop & $51(18.6 \%)$ \\
\hline Drug/chemical shop & \\
\hline Self-medication / herbal drug use & \\
\hline Days of on-set of child symptoms & \\
\hline 1 day & \\
\hline
\end{tabular}

${ }^{*}$ Clinical severity was classify using haemoglobin levels, parasitaemia, and hospital admission. 
Table 4: Multivariate Tests ${ }^{c}$ showing the effect of guardians' socio-demographic on the factors that influence child health

\begin{tabular}{|c|c|c|c|c|c|c|}
\hline & & Value & $F$ & Hypothesis df & Error df & p-value \\
\hline \multirow[t]{4}{*}{ Intercept } & Pillai's Trace & 0.997 & $2.653 \mathrm{E} 4^{\mathrm{a}}$ & 3 & 258 & $<0.0001$ \\
\hline & Wilks' Lambda & 0.003 & $2.653 \mathrm{E} 4^{\mathrm{a}}$ & 3 & 258 & $<0.0001$ \\
\hline & Hotelling's Trace & 308.545 & $2.653 \mathrm{E} 4^{\mathrm{a}}$ & 3 & 258 & $<0.0001$ \\
\hline & Roy's Largest Root & 308.545 & $2.653 \mathrm{E} 4^{\mathrm{a}}$ & 3 & 258 & $<0.0001$ \\
\hline \multirow[t]{4}{*}{ CSOC } & Pillai's Trace & 0.548 & 32.582 & 6 & 518 & $<0.0001$ \\
\hline & Wilks' Lambda & 0.458 & $41.059^{a}$ & 6 & 516 & $<0.0001$ \\
\hline & Hotelling's Trace & 1.169 & 50.093 & 6 & 514 & $<0.0001$ \\
\hline & Roy's Largest Root & 1.158 & $99.971^{\mathrm{b}}$ & 3 & 259 & $<0.0001$ \\
\hline \multirow[t]{4}{*}{$\mathrm{FPOCCH}$} & Pillai's Trace & 0.443 & 11.264 & 12 & 780 & $<0.0001$ \\
\hline & Wilks' Lambda & 0.59 & 12.541 & 12 & 682.895 & $<0.0001$ \\
\hline & Hotelling's Trace & 0.637 & 13.624 & 12 & 770 & $<0.0001$ \\
\hline & Roy's Largest Root & 0.53 & $34.439^{b}$ & 4 & 260 & $<0.0001$ \\
\hline
\end{tabular}

a. Exact statistic;

b. The statistic is an upper bound on $\mathrm{F}$ that yields a lower bound on the significance level;

c. Design: Intercept + CSOC + FPOCCH + DOOSCS + CS + MCID

NB: there is no interaction between Effects

Table 4: Continue 


\begin{tabular}{|c|c|c|c|c|c|c|}
\hline & Effect & Value & $\mathbf{F}$ & Hypothesis df & Error df & p-value \\
\hline \multirow[t]{4}{*}{ DOOSCS } & Pillai's Trace & 0.056 & 2.479 & 6 & 518 & 0.023 \\
\hline & Wilks' Lambda & 0.944 & $2.506^{\mathrm{a}}$ & 6 & 516 & 0.021 \\
\hline & Hotelling's Trace & 0.059 & 2.532 & 6 & 514 & 0.02 \\
\hline & Roy's Largest Root & 0.059 & $5.104^{b}$ & 3 & 259 & 0.002 \\
\hline \multirow[t]{4}{*}{ CS } & Pillai's Trace & 0.298 & $36.523^{a}$ & 3 & 258 & $<0.0001$ \\
\hline & Wilks' Lambda & 0.702 & $36.523^{a}$ & 3 & 258 & $<0.0001$ \\
\hline & Hotelling's Trace & 0.425 & $36.523^{a}$ & 3 & 258 & $<0.0001$ \\
\hline & Roy's Largest Root & 0.425 & $36.523^{a}$ & 3 & 258 & $<0.0001$ \\
\hline \multirow[t]{4}{*}{ MCID } & Pillai's Trace & 0.957 & 40.572 & 9 & 780 & $<0.0001$ \\
\hline & Wilks' Lambda & 0.23 & 57.908 & 9 & 628.055 & $<0.0001$ \\
\hline & Hotelling's Trace & 2.584 & 73.686 & 9 & 770 & $<0.0001$ \\
\hline & Roy's Largest Root & 2.274 & $1.971 \mathrm{E} 2^{\mathrm{b}}$ & 3 & 260 & $<0.0001$ \\
\hline
\end{tabular}

Table 5: Association between guardians' socio-demographic on the factors that influence child health 


\begin{tabular}{|c|c|c|c|c|c|c|}
\hline Source & Dependent Variable & $\begin{array}{l}\text { Type III Sum of } \\
\text { Squares }\end{array}$ & Df & $\begin{array}{l}\text { Mean } \\
\text { Square }\end{array}$ & $F$ & p-value \\
\hline \multirow[t]{4}{*}{$\begin{array}{l}\text { Corrected } \\
\text { Model }\end{array}$} & $\begin{array}{l}\text { Occupational status of } \\
\text { Guardian }\end{array}$ & $1349.090^{\mathrm{a}}$ & 13 & 103.776 & 618.435 & $<0.0001$ \\
\hline & $\begin{array}{l}\text { Educational level of } \\
\text { Guardian }\end{array}$ & $335.163^{b}$ & 13 & 25.782 & 356.971 & $<0.0001$ \\
\hline & Sex of Guardian & $45.723^{c}$ & 13 & 3.517 & & \\
\hline & $\begin{array}{l}\text { Age category of } \\
\text { Guardian }\end{array}$ & $50.351^{d}$ & 13 & 3.873 & 314.694 & $<0.0001$ \\
\hline \multirow[t]{4}{*}{ Intercept } & $\begin{array}{l}\text { Occupational status of } \\
\text { Guardian }\end{array}$ & 3229.456 & 1 & 3229.456 & $1.93 E+04$ & $<0.0001$ \\
\hline & $\begin{array}{l}\text { Educational level of } \\
\text { Guardian }\end{array}$ & 1854.812 & 1 & 1854.812 & $2.57 E+04$ & $<0.0001$ \\
\hline & Sex of Guardian & 522.811 & 1 & 522.811 & & \\
\hline & $\begin{array}{l}\text { Age category of } \\
\text { Guardian }\end{array}$ & 466.864 & 1 & 466.864 & $3.79 \mathrm{E}+04$ & $<0.0001$ \\
\hline \multirow[t]{4}{*}{ csoc } & $\begin{array}{l}\text { Occupational status of } \\
\text { Guardian }\end{array}$ & 33.224 & 2 & 16.612 & 98.997 & $<0.0001$ \\
\hline & $\begin{array}{l}\text { Educational level of } \\
\text { Guardian }\end{array}$ & 8.977 & 2 & 4.489 & 62.148 & $<0.0001$ \\
\hline & Sex of Guardian & 0 & 2 & 0 & & \\
\hline & $\begin{array}{l}\text { Age category of } \\
\text { Guardian }\end{array}$ & 0 & 2 & 0 & 0 & 1 \\
\hline
\end{tabular}

a. R Squared $=.969($ Adjusted R Squared $=.967) ;$ b. R Squared $=.947($ Adjusted R Squared $=.944)$;

b. R Squared $=1.000($ Adjusted R Squared $=1.000) ;$ d. R Squared $=.940($ Adjusted R Squared $=.937)$

Table 5: Continue 


\begin{tabular}{|c|c|c|c|c|c|c|}
\hline Source & Dependent Variable & $\begin{array}{l}\text { Type III Sum of } \\
\text { Squares }\end{array}$ & Df & $\begin{array}{l}\text { Mean } \\
\text { Square }\end{array}$ & $F$ & p-value \\
\hline \multirow[t]{4}{*}{$\mathrm{FPOCCH}$} & $\begin{array}{l}\text { Occupational status of } \\
\text { Guardian }\end{array}$ & 20.028 & 4 & 5.007 & 29.838 & $<0.0001$ \\
\hline & $\begin{array}{l}\text { Educational level of } \\
\text { Guardian }\end{array}$ & 0.62 & 4 & 0.155 & 2.146 & 0.076 \\
\hline & Sex of Guardian & 0 & 4 & 0 & & \\
\hline & $\begin{array}{l}\text { Age category of } \\
\text { Guardian }\end{array}$ & 0.486 & 4 & 0.122 & 9.877 & $<0.0001$ \\
\hline \multirow[t]{4}{*}{ DoOsCS } & $\begin{array}{l}\text { Occupational status of } \\
\text { Guardian }\end{array}$ & 2.569 & 2 & 1.284 & 7.655 & $<0.0001$ \\
\hline & $\begin{array}{l}\text { Educational level of } \\
\text { Guardian }\end{array}$ & 0 & 2 & 0 & 0 & 1 \\
\hline & Sex of Guardian & 0 & 2 & 0 & & \\
\hline & $\begin{array}{l}\text { Age category of } \\
\text { Guardian }\end{array}$ & 0 & 2 & 0 & 0 & 1 \\
\hline \multirow[t]{4}{*}{ CS } & $\begin{array}{l}\text { Occupational status of } \\
\text { Guardian }\end{array}$ & 18.455 & 1 & 18.455 & 109.977 & $<0.0001$ \\
\hline & $\begin{array}{l}\text { Educational level of } \\
\text { Guardian }\end{array}$ & 0 & 1 & 0 & 0 & 1 \\
\hline & Sex of Guardian & 0 & 1 & 0 & & \\
\hline & $\begin{array}{l}\text { Age category of } \\
\text { Guardian }\end{array}$ & 0 & 1 & 0 & 0 & 1 \\
\hline
\end{tabular}

Table 5: Continue 


\begin{tabular}{|c|c|c|c|c|c|c|}
\hline Source & Dependent Variable & $\begin{array}{l}\text { Type III Sum of } \\
\text { Squares }\end{array}$ & Df & $\begin{array}{l}\text { Mean } \\
\text { Square }\end{array}$ & $\mathbf{F}$ & p-value \\
\hline \multirow[t]{4}{*}{ MCID } & $\begin{array}{l}\text { Occupational status of } \\
\text { Guardian }\end{array}$ & 5.954 & 3 & 1.985 & 11.827 & $<0.0001$ \\
\hline & $\begin{array}{l}\text { Educational level of } \\
\text { Guardian }\end{array}$ & 4.2 & 3 & 1.4 & 19.384 & $<0.0001$ \\
\hline & Sex of Guardian & 9.644 & 3 & 3.215 & & \\
\hline & Age category of Guardian & 7.111 & 3 & 2.37 & 192.593 & $<0.0001$ \\
\hline \multirow[t]{4}{*}{ Error } & $\begin{array}{l}\text { Occupational status of } \\
\text { Guardian }\end{array}$ & 43.629 & 260 & 0.168 & & \\
\hline & $\begin{array}{l}\text { Educational level of } \\
\text { Guardian }\end{array}$ & 18.778 & 260 & 0.072 & & \\
\hline & Sex of Guardian & 0 & 260 & 0 & & \\
\hline & Age category of Guardian & 3.2 & 260 & 0.012 & & \\
\hline \multirow[t]{4}{*}{ Total } & $\begin{array}{l}\text { Occupational status of } \\
\text { Guardian }\end{array}$ & 5579 & 274 & & & \\
\hline & $\begin{array}{l}\text { Educational level of } \\
\text { Guardian }\end{array}$ & 2796 & 274 & & & \\
\hline & Sex of Guardian & 922 & 274 & & & \\
\hline & Age category of Guardian & 877 & 274 & & & \\
\hline
\end{tabular}

Table 5: Continue

\begin{tabular}{|c|c|c|c|c|c|c|}
\hline Source & Dependent Variable & $\begin{array}{l}\text { Type III Sum of } \\
\text { Squares }\end{array}$ & Df & $\begin{array}{l}\text { Mean } \\
\text { Square }\end{array}$ & $F$ & $\begin{array}{l}\mathrm{p}- \\
\text { value }\end{array}$ \\
\hline \multirow[t]{4}{*}{$\begin{array}{l}\text { Corrected } \\
\text { Total }\end{array}$} & $\begin{array}{l}\text { Occupational status of } \\
\text { Guardian }\end{array}$ & 1392.719 & 273 & & & \\
\hline & $\begin{array}{l}\text { Educational level of } \\
\text { Guardian }\end{array}$ & 353.942 & 273 & & & \\
\hline & Sex of Guardian & 45.723 & 273 & & & \\
\hline & Age category of Guardian & 53.551 & 273 & & & \\
\hline
\end{tabular}

Table 6: Multilayer Perceptron analysis showing patterns between guardians' socio-demographic characteristics and the factors that influence child health 


\begin{tabular}{|c|c|c|}
\hline \multicolumn{3}{|l|}{ Case Processing Summary } \\
\hline Training (\%/N) & \multicolumn{2}{|l|}{$67.9 / 186$} \\
\hline Testing $(\% / \mathrm{N})$ & \multicolumn{2}{|l|}{$32.1 / 88$} \\
\hline Valid $(\% / N)$ & \multicolumn{2}{|l|}{$100.0 / 274$} \\
\hline \multicolumn{3}{|l|}{ Network Information } \\
\hline \multirow[t]{5}{*}{ Input Layer } & Factors & Factor ID \\
\hline & $\mathrm{FPOCCH}$ & 1 \\
\hline & DOOSCS & 2 \\
\hline & CS & 3 \\
\hline & MCID & 4 \\
\hline \multirow[t]{3}{*}{ Hidden Layer(s) } & Number of Units ${ }^{a}$ & 17 \\
\hline & Number of Hidden Layers & 1 \\
\hline & Number of Units in Hidden Layer $1^{a}$ & 9 \\
\hline Activation Function & \multicolumn{2}{|l|}{ Hyperbolic tangent } \\
\hline \multirow[t]{6}{*}{ Output Layer } & Dependent Variables & Variables ID \\
\hline & OCSG & 1 \\
\hline & EDULG & 2 \\
\hline & SOG & 3 \\
\hline & AGECOG & 4 \\
\hline & Number of Units & 4 \\
\hline Rescaling Method for Scale Dependents & \multicolumn{2}{|l|}{ Standardized } \\
\hline Activation Function & \multicolumn{2}{|l|}{ Identity } \\
\hline Error Function & \multicolumn{2}{|l|}{ Sum of Squares } \\
\hline
\end{tabular}

a. Excluding the bias unit

b. Error computations are based on the testing sample. 
Table 6: Continue

\begin{tabular}{|lll|}
\hline Model Summary & & \\
\hline Training & Sum of Squares Error & 13.899 \\
\hline & Average Overall Relative Error & 0.038 \\
\hline Relative Error for Scale Dependents & OCSG & 0.043 \\
\hline & EDULG & 0.058 \\
\hline & SOG & 0 \\
\hline Stopping Rule Used & AGECOG & 0.05 \\
\hline Training Time & 1 consecutive step(s) with no decrease in error ${ }^{\mathrm{b}}$ & \\
\hline
\end{tabular}

Figures 


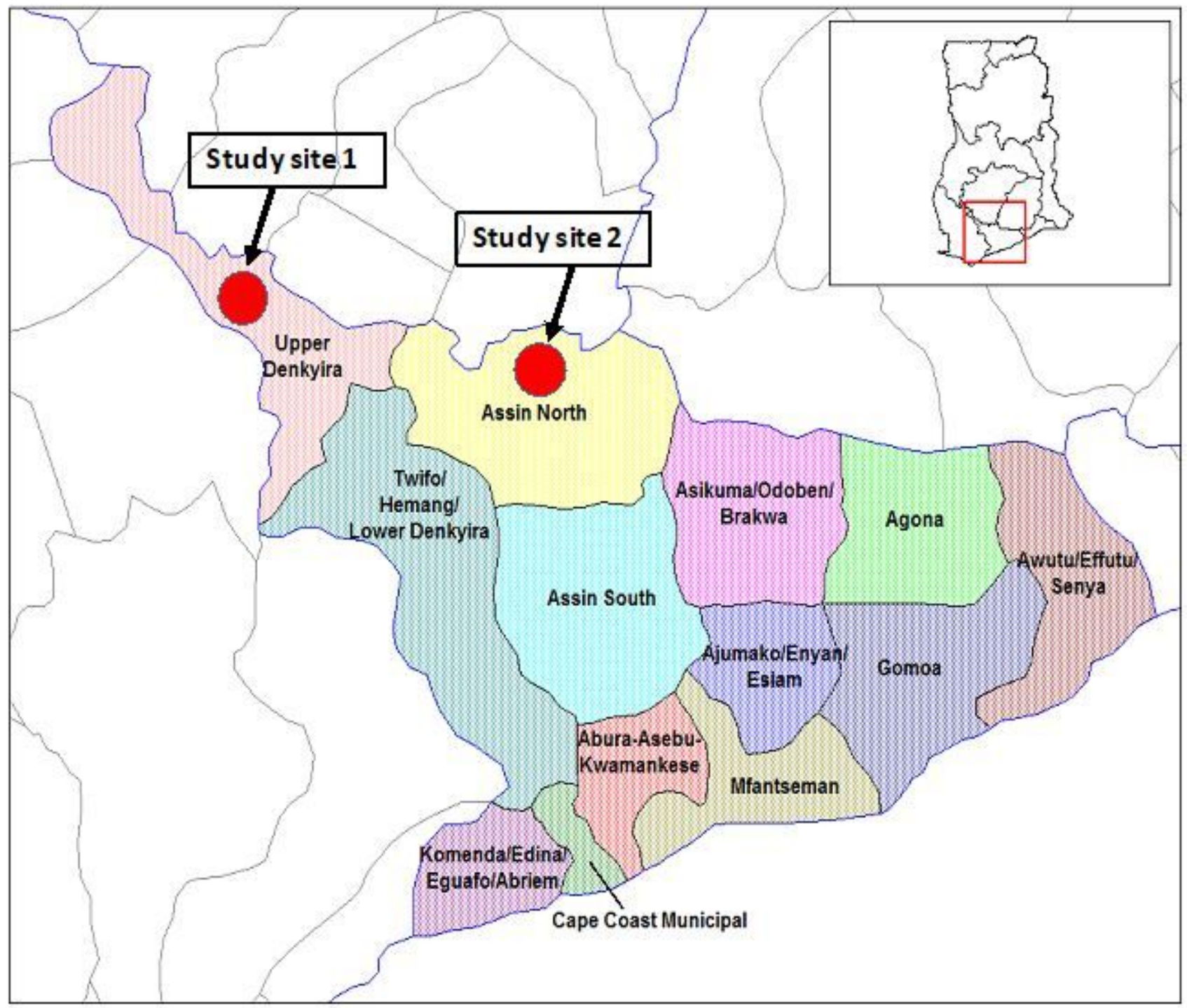

Figure 1

The map of Central region of Ghana and the sample collection sites adapt from Google Map Note: The designations employed and the presentation of the material on this map do not imply the expression of any opinion whatsoever on the part of Research Square concerning the legal status of any country, territory, city or area or of its authorities, or concerning the delimitation of its frontiers or boundaries. This map has been provided by the authors. 


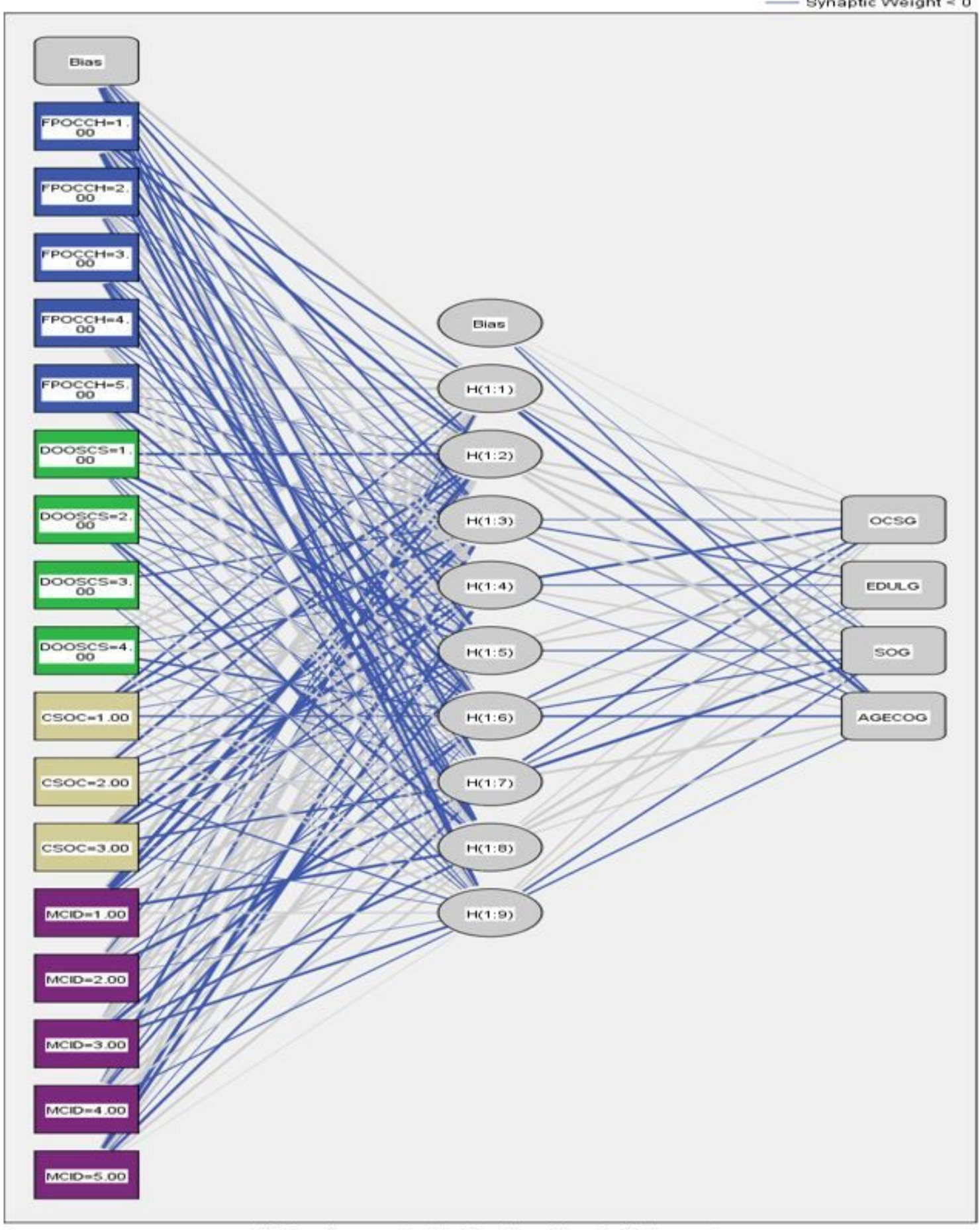

Hidden layer activation function: Hyperbolic tangent

Output layer activation function: Identity

\section{Figure 2}

Multilayer Perceptron network for pattern recognition between guardians' socio-demographic characteristics and the factors that influence child health 


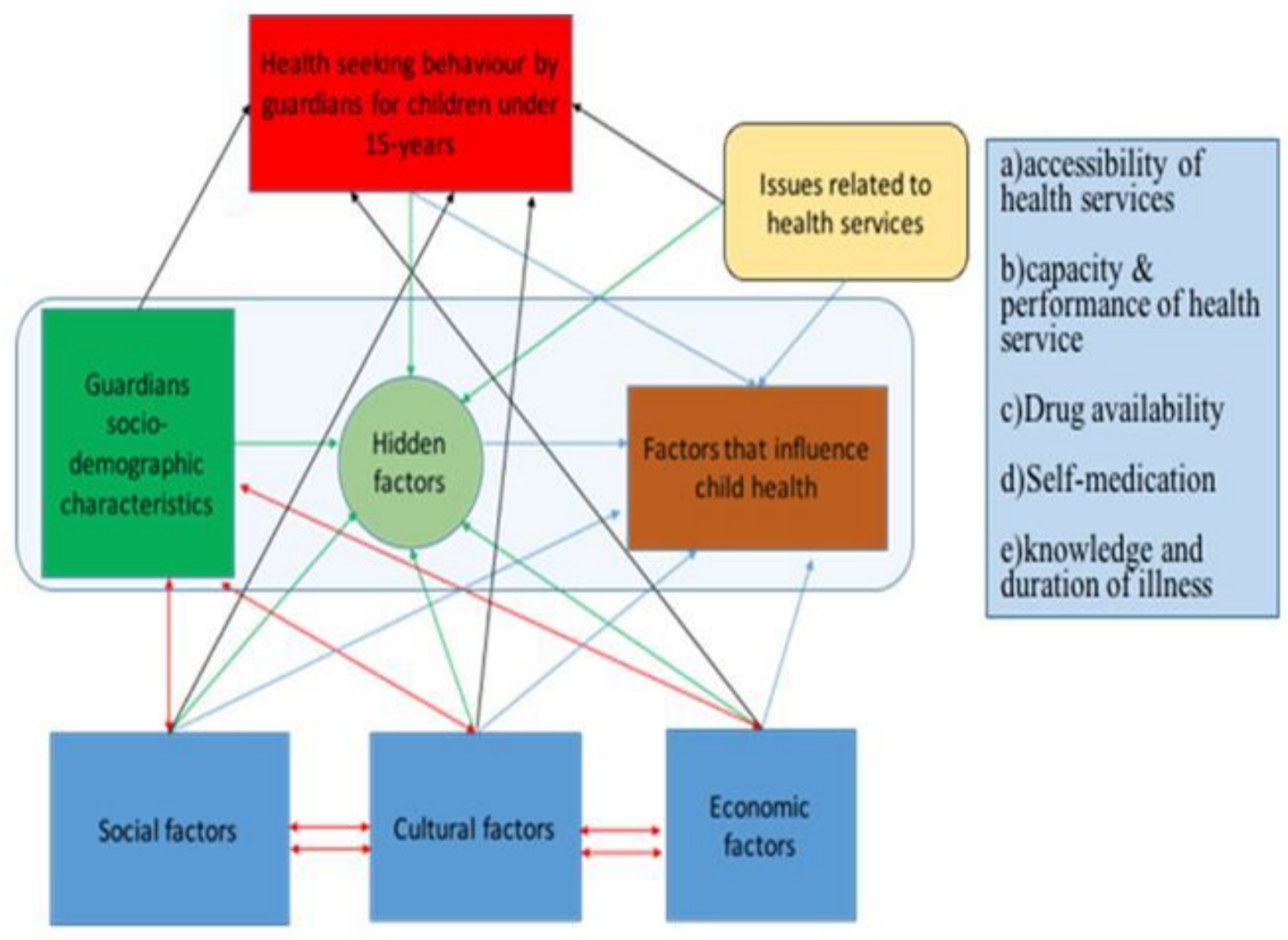

\begin{tabular}{|c|c|c|}
\hline a)Social networks & a)Cultural beliefs & a)Family income \\
\hline $\begin{array}{l}\text { b)Family size } \\
\text { c) Solid role in } \\
\text { decisions related to } \\
\text { child health }\end{array}$ & $\begin{array}{l}\text { b)Traditional } \\
\text { interventions } \\
\text { c) Expectations of } \\
\text { aging }\end{array}$ & $\begin{array}{l}\text { b) Treatment cost } \\
\text { c) health insurance } \\
\text { subscription }\end{array}$ \\
\hline $\begin{array}{l}\text { d) Number of sick } \\
\text { children }\end{array}$ & $\begin{array}{l}\text { d) Ethnicity } \\
\text { e)Absence of head of } \\
\text { household }\end{array}$ & \\
\hline
\end{tabular}

\section{Figure 3}

Model network of socio-economic progenitors that impact on the factors that influence child health in malaria endemic area 